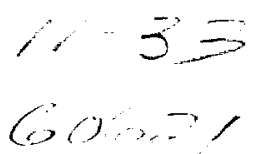

NASA Technical Memorandum 107244

\title{
Experimental and Theoretical Study of Parasitic Leakage/Resonance in a K/Ka-Band MMIC Package
}

Jong-Gwan Yook and Linda P.B. Katehi

University of Michigan

Ann Arbor, Michigan

Rainee N. Simons

NYMA, Inc.

Brook Park, Ohio

Kurt Shalkhauser

Lewis Research Center

Cleveland, Ohio

Prepared for the

1996 IEEE MTT-S International Microwave Symposium

San Francisco, California, June 16-20, 1996

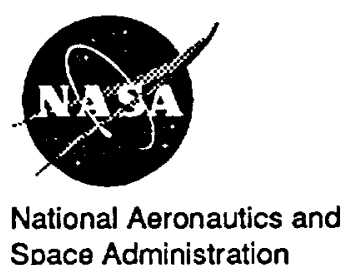

Space Administration 


\title{
Experimental and Theoretical Study of Parasitic Leakage/Resonance in a K/Ka-Band MMIC Package
}

\author{
Jong-Gwan Yook and Linda P. B. Katehi \\ Radiation Laboratory \\ The University of Michigan, Ann Arbor, MI 48109-2122, U. S. A. \\ Tel: 313-764-0502, Fax: 313-747-2122, Email: yookjong@engin.umich.edu \\ Rainee N. Simons and Kurt Shalkhauser \\ NASA Lewis Research Center NYMA Group, NASA Lewis Research Center \\ Cleveland, $\mathrm{OH} 44135$
}

\begin{abstract}
In this paper, electromagnetic leakage and spurious resonances in a $\mathrm{K} / \mathrm{Ka}$ band (18 - $40 \mathrm{GHz})$ MMIC hermetic package designed for a phase shifter chip are studied using the finite element method (FEM) and the numerical simulation results are compared with measured data. Both in measured and calculated data several spurious resonances are observed in the 18 to $24 \mathrm{GHz}$ region and the origin of this phenomenon is identified by virtue of the modeling capability of the FEM.
\end{abstract}

\section{INTRODUCTION}

High performance packages, especially for microwave and millimeter-wave integrated circuit application, should satisfy stringent mechanical, electrical and environmental requirements. From a mechanical and environmental point of view, a package should provide protection to the internal circuits from the hostile surroundings such as vibration, temperature fluctuation, heat and humidity. Furthermore, packages are required to exhibit minimum insertion loss, good isolation between the ports as well as electromagnetic shielding for minimum interference (EMI/EMC) $[1,2]$. Another important electrical requirement of a package is non-invasiveness with respect to circuit performance [3]; a package fails electrically if parasitic cavity resonances deteriorate circuit performance. As a result of all of these requirements, successful development of a high frequency package requires careful design strategies.
Recently, low cost high performance MMIC packages have been developed by using approximate equivalent circuit models or empirical intuition $[4,5]$. Even though these packages reveal satisfying performance in a certain frequency band, they fail as operating frequency increases. Furthermore, their use in commercial applications is limited due to difficulties in the manufacturing process and the lack of accurate modeling capability. More recently, there were a few reports of using the frequency and time domain full wave electromagnetic simulation tools [6]-[8] for more accurate modeling and characterization of the package's electrical performance, even though they are limited by heavy computational burden or simplified analysis.

In this paper, we study the performance and parasitic effects of a $\mathrm{K} / \mathrm{Ka}$-band hermetic package designed for a MMIC phase shifter. In addition, the effects of the various features of the package, such as via holes, DC bias lines, bonding wires, structural asymmetries, and even the effect of the test fixture on the circuit performance are extensively investigated. For the electromagnetic characterization of the Ka-Band MMIC package, a three dimensional FEM technique is applied and all of the computations are performed using a high performance parallel computer (IBM SP2). The modeled characteristics are compared with experimental results and shows very good agreement. To the best of our knowledge, this is the first comprehensive FEM model for an existing millimeter-wave package. This model has the potential to predict the performance of other types of packages including multi-chip modules. These packages have application in the emerging field 
of wireless communications.

\section{Modeling of the Package}

A K/Ka-band MMIC package fabricated by Hughes Aircraft Co. for NASA Lewis Research Center is shown in Fig. 1. The package has $50 \Omega$ microstrip input/output lines for the RF signal and a set of five lines on either sides for DC bias. In addition, a set of filled vias tie the top and bottom perfect electric conductor (PEC) ground planes together to provide mechanical strength and an electromagnetic shielding environment. The package is fabricated from alumina (92\% pure, $\left.\epsilon_{r}=9.5\right)$ using the HTCC process. To characterize the package, a $50 \Omega$ thru line is placed in the recess at the center of the package as shown and is bond-wired to the microstrip lines on either sides. As one can observe in the figure, the package is not symmetric due to the displaced via holes and the input/output microstrip lines. This asymmetry is attributed to the specific geometry of the MMIC component the package intends to house.

Strictly speaking, this package is not completely shielded electromagnetically and as a result the packaged circuits are exposed to a semi-open environment. For the simulation of this environment, artificial absorbing layers [9] have been designed using lossy isotropic dielectrics. The performance of the absorber is controlled by assigning certain amount of losses in the absorbing material and by specifying its thickness. It is well known that this type of absorber performs well for near-normal incident fields.

\section{NUMERICAL AND EXPERIMENTAL RESULTS}

The package is theoretically analyzed under two different operating conditions. In the first case, it is assumed that the package performs ideally and the effect of the test equipment is negligible. In the second case, however, the package is analyzed under the effects of the test fixture. The results of these two analysis are presented below and are used to quantify the effect of radiation leakage and spurious resonances as well as the influence of the test fixture on the package performance.

\section{III-A. Modeling of the isolated package}

In this section, the performance of the package is calculated without the presence of the test fixture and Sparameters are shown in Fig. 2. As one can observe in the figure, the package reveals very good performance with less than $-10.0 \mathrm{~dB}$ return loss in the whole frequency range. It is also noted that no cavity or spurious resonances are observed even though the size of the overall package becomes larger than the guided wavelength at higher frequencies. This phenomenon can be explained as an effect of the poor electromagnetic hermeticity of the given package. Even though the package could provide excellent mechanical/environmental protections and hermeticity, the side walls formed by the 12 vertical via holes between the DC bias lines do not provide a solid electromagnetic shield. However, due to this poor EM hermeticity and subsequent leakage, Fig. 3, the cavity resonances are not strong as it can be seen in Fig. 5. Further study of the package has revealed that the performance can be substantially improved when this package is built in a symmetric fashion.

\section{III-B. MODELING OF TEST FiXTURE/PACKAGE COM- BINATION}

The package is now modeled by taking into consideration the test fixture to quantify the leakage and spurious resonances. The test fixture is modeled by using PEC walls which have an opening at the center for the input/output coaxial connectors and half PEC walls and artificial absorbers for two other sides. The half PEC walls are designed for the simulation of the recess depth of the test fixture and absorber is placed on top of the half PEC wall. The measured and computed scattering parameters for the package placed in the test fixture show very good agreement as illustrated in Fig 4. As it can be observed, the overall structure including the package and test fixture suffers from spurious resonances in the low frequency region $(18-24 \mathrm{GHz})$ but it exhibits a good performance in the rest of the frequency range.

The resonance phenomenon can be understood by investigating the electromagnetic field distribution at various frequencies as shown in Fig. 5. The first figure in Fig. 5 is computed at $\mathbf{f}=20.5 \mathrm{GHz}$ where $\left|S_{11}\right|$ has a peak (4 (a)) and reveals energy leakage through the in/output feedthru lines and between the via holes resulting in high insertion loss. Also, it is observed that at some frequencies EM fields are strongly concentrated in the dielectric ring on top of the microstrip feedthru lines and along the DC bias lines indicating occurrence of the spurious resonances. The second figure shows the field distribution at $29.5 \mathrm{GHz}$ 
where $\left|S_{11}\right|$ exhibits a dip. The calculated results show that the concentration of the electromagnetic field in the microstrip line.

\section{CONCLUSIONS}

In this paper, 18 to $40 \mathrm{GHz}$ hermetic package is analyzed and fully characterized both experimentally and theoretically. Furthermore, the FEM accurately predicts the energy leakage and spurious resonances which degrade the package performance. In addition to the modeling, our study has also demonstrated the need for accurate theoretical and experimental characterization of the package to avoid misinterpretation of measured performance. The package exhibits excellent performance over the $\mathrm{K} / \mathrm{Ka}$-Band with insertion loss less than $2 \mathrm{~dB}$. To the best of our knowledge, this is the first comprehensive study of RF leakage and resonances in a millimeter-wave package.

\section{ACKNOWLEDGMENT}

This work was partially supported by NASA Lewis Research Center. Also, the authors would like to thank the Maui High Performance Computing Center ( $\mathrm{MH}-$ PCC) and the University of Michigan Center for Parallel Computing (CPC), which is partially funded by NSF grant CDA-92-14296 and the Ford Motor Company, for the use of their computational facilities.

\section{References}

[1] Linda P. B. Katehi, "The Role of EM Modeling in Integrated Packaging," pp.982-985, 1992 IEEE AP-S Digest, July 1992 .

[2] H. J. Kuno and T. A. Midford, "The Evolution of MMIC Packaging," pp.1005-1008, 1992 IEEE AP-S Digest, July 1992.

[3] D. W. Griffin and A. J. Parfitt, "Electromagnetic Design Aspects of Packages for Phased Array Modules That May Incorporate Monolithic Antenna Elements," pp. 986-989, 1992 IEEE AP-S Digest, July 1992.

[4] Bernhard A. Ziegner, "High Performance MMIC Hermetic Packaging," Microwave Journal, pp. 133-139, Nov. 1986

[5] Howard Bierman, "Designers Strive for Low Cost MMIC Packages," Microwave Journal, pp. 100-106, Sep. 1992.

[6] Jong-Gwan. Yook, N. Dib, E. Yasan, and L. Katehi, "A study of Hermetic Transitions for Microwave Packages," 1995 IEEE MTT-S Int. Microwave Symp. Digest, pp.1579-1582, May 1995.

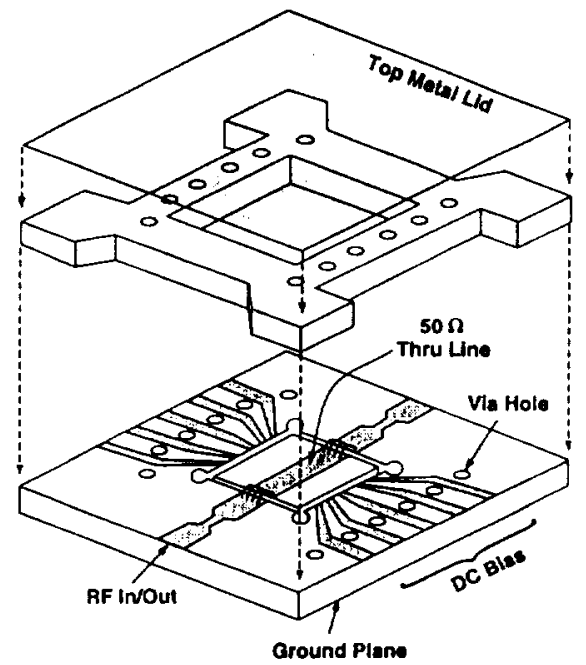

Figure 1: Schematic diagram of the K/Ka-band hermetic package designed and manufactured for a MMIC phase shifter chip.

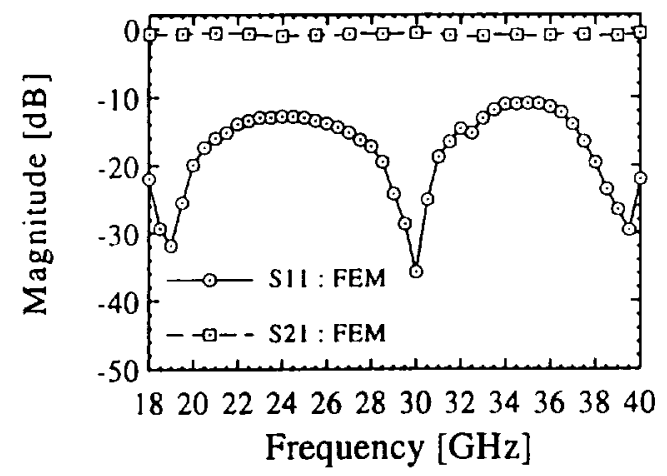

Figure 2: Computed scattering parameters for the isolated asymmetric package.

[7] J. Gipprich, L. Dickens, B. Hayes, and F. Sacks, "A Compact 8-14 GHz LTCC Stripline Coupler Network for High Efficiency Power Combining with Better Than $82 \%$ Combining efficiency," 1995 IEEE MTT. $S$ Int. Microwave Symp. Digest, pp.1583-1586, May 1995.

[8] M. Rittweger, M. Werthen, J. Kunisch, I. Wolff, P. Chall, B. Balm, and P. Lok, "3D FDTD Analysis of s SOT353 Package Containing a Bipolar Wideband Cascode Transistor Using Compression Approach," 1995 IEEE MTT-S Int. Microwave Symp. Digest, pp.1587-1590, May 1995.

[9] Jong-Gwan Yook and Iinda P. B. Katehi, "An Application of an Artificial Absorber to the MMIC Problem." IEEE Trans. Microwave Theory Tech. (submitted) 
Electric Field Distmbution in Pachage at $205 \mathrm{GHi}$
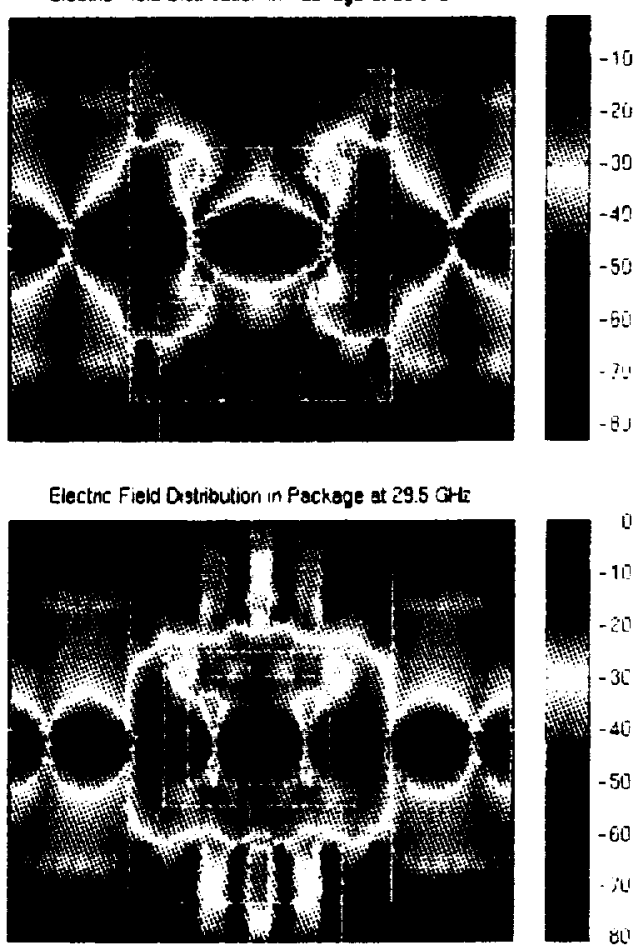

Figure 3: Vertical electric field distribulion (dB scale) at $\mathrm{f}=20.5 \mathrm{GHz}$ and 24.5 (iHz in the isolated asy'mmetric hermetic package

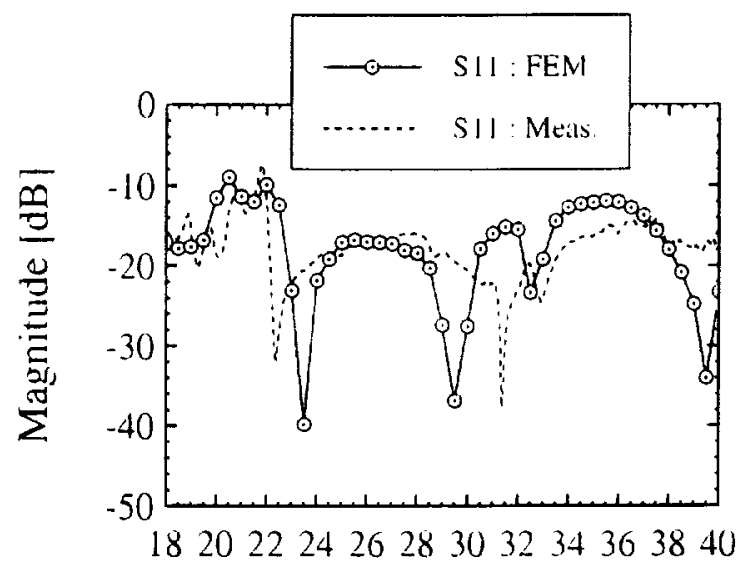

Frequency $[\mathrm{GH} z]$

Figure t: (a)

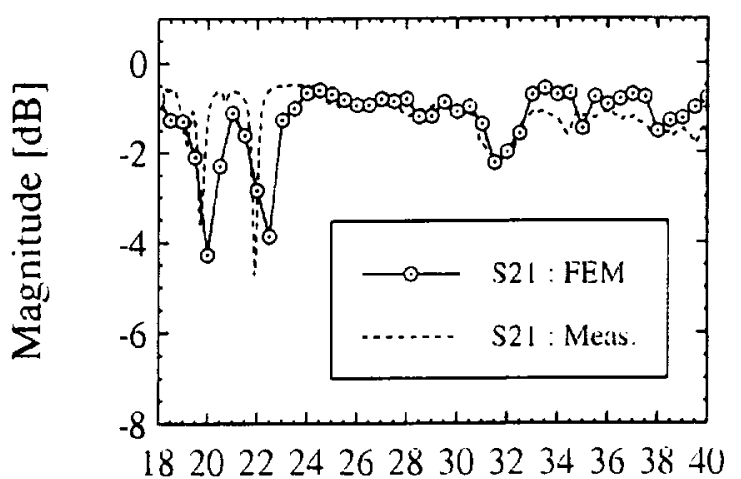

Frequency $[\mathrm{GHz}]$

(1)!

Figure 4: Measured and compuled scatleliug paraull. eters for the asymmetric package residing in the thest fixture. (a) $\left|S_{11}\right|$, (b) $\mid S_{21}$ !
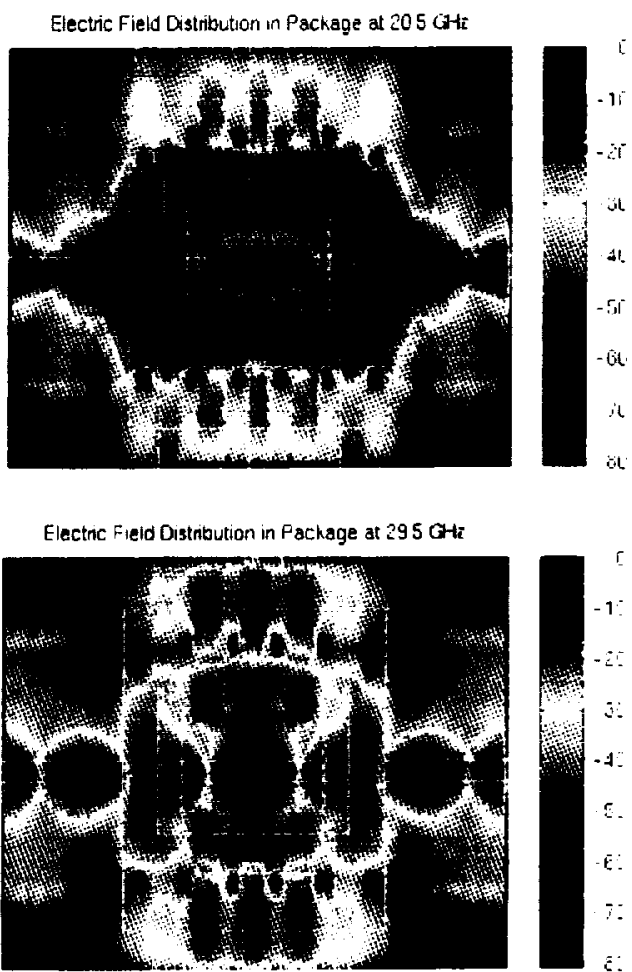

Figure 5: Vertical electric field distribution (dB soale ) in the asymmetric hermetic package placed in the test fixtule at $f=20.5 \mathrm{GHz}$ and $29.5 \mathrm{CiHz}$ PBCs are localed outside the packige lo moile lihe lest fixtull. 



\begin{tabular}{|c|c|c|c|c|}
\hline \multicolumn{3}{|c|}{ REPORT DOCUMENTATION PAGE } & & $\begin{array}{l}\text { Form Approved } \\
\text { OMB No. 0704-0188 }\end{array}$ \\
\hline \multicolumn{5}{|c|}{ 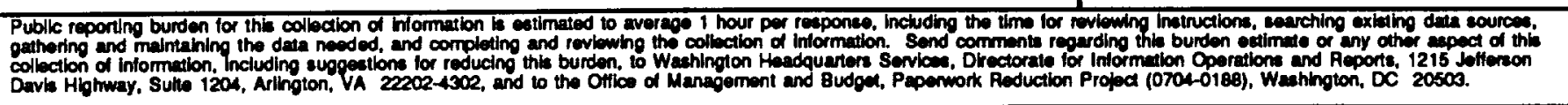 } \\
\hline 1. AGENCY USE ONLY (Leave blank) & $\begin{array}{r}\text { 2. REPORT DATE } \\
\text { May } 1996\end{array}$ & \multicolumn{3}{|c|}{$\begin{array}{l}\text { 3. REPORT TYPE AND DATES COVERED } \\
\text { Technical Memorandum }\end{array}$} \\
\hline \multicolumn{3}{|c|}{$\begin{array}{l}\text { 4. TITLE AND SUBTILE } \\
\text { Experimental and Theoretical Study of Parasitic Leakage/Resonance in a } \\
\text { K/Ka-Band MMIC Package }\end{array}$} & \multicolumn{2}{|c|}{ 5. FUNDING NUMBERS } \\
\hline \multicolumn{3}{|c|}{$\begin{array}{l}\text { B. AUTHOR(S) } \\
\text { Jong-Gwan Yook, Linda P.B. Katehi, Rainee N. Simons, and Kurt Shalkhauser }\end{array}$} & \multicolumn{2}{|c|}{ WU-506-44-2C } \\
\hline \multicolumn{3}{|c|}{$\begin{array}{l}\text { 7. PERFORMING ORGANUZATION NAME(S) AND ADDAESS(ES) } \\
\text { National Aeronautics and Space Administration } \\
\text { Lewis Research Center } \\
\text { Cleveland, Ohio } 44135-3191\end{array}$} & 8. PEI & $\begin{array}{l}\text { OPMANG OAGANIZATION } \\
0292\end{array}$ \\
\hline \multicolumn{3}{|c|}{$\begin{array}{l}\text { 9. SPONSORINGNONUTORING AGENCY MAME(S) AND ADDRESS(ES) } \\
\text { National Aeronautics and Space Administration } \\
\text { Washington, D.C. 20546-0001 }\end{array}$} & \multicolumn{2}{|c|}{$\begin{array}{l}\text { 10. SPONSOFINGMONITORING } \\
\text { AGENCY REPORT NUMBER } \\
\text { NASA TM-107244 }\end{array}$} \\
\hline \multicolumn{5}{|c|}{$\begin{array}{l}\text { 11. SUPPLEMENTARY NOTES } \\
\text { Prepared for the } 1996 \text { IEEE MTT-S International Microwave Symposium, San Francisco, California, June 16-20, } 1996 . \\
\text { Partially funded by NSF grant CDA-92-14296 and the Ford Motor Company. Jong-Gwan Yook and Linda P.B. Katehi, } \\
\text { University of Michigan, Radiation Laboratory, Ann Arbor, Michigan 48109-2122 (work funded under NASA Grant NAG- } \\
\text { 1807); Rainee N. Simons, NYMA, Inc., 2001 Aerospace Parkway, Brook Park, Ohio } 44142 \text { (work funded under NASA } \\
\text { Contract NAS3-27186); and Kurt Shalkhauser, NASA Lewis Research Center. Responsible person, Kurt Shalkhauser, } \\
\text { organization code 5640, (216) 433-3452. }\end{array}$} \\
\hline \multicolumn{3}{|c|}{$\begin{array}{l}\text { 12. DISTRIBUTIONAVAILABILTY STATEMENT } \\
\text { Unclassified - Unlimited } \\
\text { Subject Category } 33 \\
\text { This publication is available from the NASA Center for AeroSpace Information, (301) 621-0390. }\end{array}$} & \multicolumn{2}{|c|}{ 12b. DISTRIBUTION CODE } \\
\hline \multicolumn{5}{|c|}{$\begin{array}{l}\text { In this paper, electromagnetic leakage and spurious resonances in a } \mathrm{K} / \mathrm{Ka} \text {-band (18-40 GHz) MMIC hermetic package } \\
\text { designed for a phase shifter chip are studied using the finite element method (FEM) and the numerical simulation results } \\
\text { are compared with measured data. Both in measured and calculated data several spurious resonances are observed in the } \\
18 \text { to } 24 \mathrm{GHz} \text { region and the origin of this phenomenon is identified by virtue of the modeling capability of the FEM. }\end{array}$} \\
\hline \multirow{2}{*}{\multicolumn{4}{|c|}{$\begin{array}{l}\text { 14. SUBJECT TERMS } \\
\text { Microwave circuits; Electronic packaging; Antenna arrays }\end{array}$}} & $\begin{array}{l}\text { 15. NUMBER OF PAGES } \\
6\end{array}$ \\
\hline & & & & \begin{tabular}{|l} 
16. PRICE CODE \\
A02 \\
\end{tabular} \\
\hline $\begin{array}{l}\text { 17. SECURITY CLASSIFICATION } \\
\text { OF REPORT } \\
\text { Unclassified }\end{array}$ & $\begin{array}{l}\text { 18. SECURTY CLASSIFICATION } \\
\text { OF THIS PAGE } \\
\text { Unclassified }\end{array}$ & $\begin{array}{l}\text { 19. SECURTTY CLASSIFICAT } \\
\text { OF ABSTRACT } \\
\text { Unclassified }\end{array}$ & & 20. LIMTTATION OF ABSTRACT \\
\hline
\end{tabular}



, 


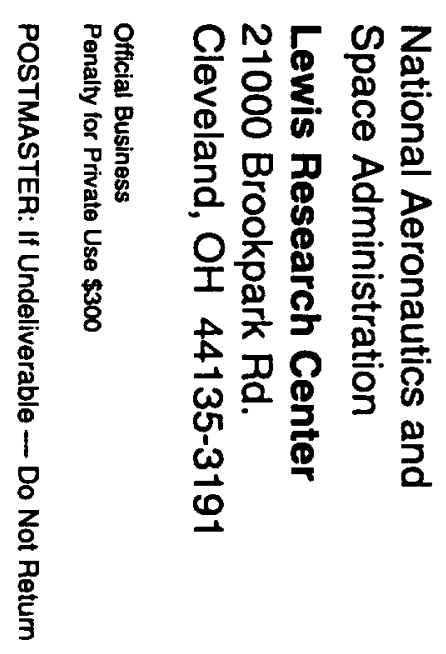

